\title{
Lyophilized allogeneic bone tissue as an antibiotic carrier
}

\author{
Débora C. Coraça-Huber • Christoph G. Ammann • Michael Nogler • Manfred Fille • \\ Lars Frommelt · Klaus-Dieter Kühn · Christian Fölsch
}

Received: 11 May 2016/Accepted: 1 September 2016/Published online: 8 September 2016

(C) The Author(s) 2016. This article is published with open access at Springerlink.com

\begin{abstract}
The rising number of primary joint replacements worldwide causes an increase of revision surgery of endoprostheses due bacterial infection. Revision surgery using non-cemented implants seems beneficial for the long-term outcome and the use of antibiotic-impregnated bone grafts might control the infection and give a good support for the implant. In this study we evaluated the release of antibiotics from fresh-frozen and lyophilized allogeneic bone grafts. Lyophilized bone chips and fresh frozen bone chips were mixed with gentamicin sulphate, gentamicin palmitate, vancomycin, calcium carbonate/calcium sulphate impregnated with gentamicin sulphate, and calcium carbonate/calcium sulphate bone substitute material impregnated with vancomycin. The efficacy of each preparation was measured by drug release tests and bacterial susceptibility using $B$. subtilis, $S$. aureus
\end{abstract}

D. C. Coraça-Huber $(\bowtie)$ C C. G. Ammann · M. Nogler Experimental Orthopaedics, Department of Orthopaedic Surgery, Medical University of Innsbruck, Innrain 36, 6020 Innsbruck, Austria

e-mail: debora.coraca-huber@i-med.ac.at

M. Fille

Division of Hygiene and Medical Microbiology, Medical University Innsbruck, Schöpfstr. 41, 3rd Floor, Innsbruck, Austria

L. Frommelt

Institute for Infectiology, Clinical Microbiology and

Hospital Care, ENDO Clinic Hamburg, Holstenstraße 2,

Hamburg, Germany and methicillin-resistant Staphylococcus aureus. The release of gentamicin from lyophilized bone was similar to the release rate from fresh frozen bone during all the experimental time. That fact might be related to the similar porosity and microstructure of the bone chips. The release of gentamicin from lyophilized and fresh frozen bone was high in the first and second day, decreasing and keeping a low rate until the end of the second week. Depending on the surgical strategy either polymethylmethacrylate or allogeneic bone are able to deliver sufficient concentrations of gentamicin to achieve bacterial inhibition within two weeks after surgery. In case of uncemented revision of joint replacements allogeneic bone is able to deliver therapeutic doses of gentamicin and peak levels immediately after implantation during a fortnight. The use of lyophilized and fresh frozen bone

\footnotetext{
K.-D. Kühn

Department of Orthopaedics and Orthopaedic Surgery, Medical University Graz, Auenbruggerplatz 5, Graz, Austria

C. Fölsch

Department of Orthopaedics and Orthopaedic Surgery, Medical University of Giessen, Baldingerstraße, Marburg, Germany
} 
allografts as antibiotic carriers is recommended for prophylaxis of bone infection.

Keywords Bone grafts - Antibiotics - Lyophilized bone chips $\cdot$ Local delivery $\cdot$ Joint infection

\section{Introduction}

Bone grafts are used for reconstructing bone defects caused by implant associated complications, trauma and tumors (Putzer et al. 2011; Hinsenkamp et al. 2012). While autografts can be used, donor site morbidity can be avoided using allografts. (Barbour and King 2003; Butler et al. 2005; Haimi et al. 2008). Bone grafts might derive from post mortem donors or might be donated from femoral heads of living patients undergoing hip arthroplasty creating bone chips to fill bone defects during revision surgery of joint replacements since impaction bone grafting increases primary stability and bone stock which is essential for the longevity of the implant.

However, fresh frozen bone chips bear a higher risk of transmission of diseases and local contamination compared with processed bone grafts (Brewster et al. 1999; Hofmann et al. 2005). Surgery with bone allografts is complex and time-consuming; therefore it is per se prone to a higher infection rate (2.0-2.5\%) (Blom et al. 2003; Parvizi et al. 2007, 2008). Additionally, the impaction used for placing bone transplants can disrupts the local circulation and reduce the bone ingrowth (Tagil and Aspenberg 1998; Duffy et al. 2007; Buttaro et al. 2012; Ding et al. 2015). In the case of a site infection, systemically administered antibiotics cannot reach the infected bone graft (Isefuku et al. 2003). As a known complication factor, biofilms can be formed on the surface of foreign materials thus increasing antibiotic resistance (Coraça-Huber et al. 2012a, b). Staphylococcus epidermidis and Staphylococcus aureus are the germs which mostly colonize implant surfaces (Christensen et al. 1989).

The number of infection related to multi resistant bacteria is increasing (Ascherl 2010). Also, biofilm forming bacteria is a major concern for treatment of implant-related infections (Costerton et al. 1999; Patel 2005; Frommelt 2006; Esteban et al. 2010; CoraçaHuber et al. 2012a). Biofilm has been defined as multicellular community composed of prokaryotic and or eukaryotic cells embedded in matrix (Frommelt 2004; Esteban et al. 2010). In this case, sessile bacteria become antibiotic-resistant making treatment and diagnosis difficult (Patel 2005). Antibiotic treatment are directed against planktonic bacteria which relieves symptoms but does not cure the infection and therefore might delay adequate treatment (Frommelt 2006). High antibiotic concentrations at the implantation site, immediately available after surgery, should prevent development of biofilm.

Antibiotics delivered from an implanted biomaterial can be potentially used to prevent infections caused by biofilm formation, providing high concentrations of antibiotics at the surgical site without local or systemic toxicity. In addition, these materials should be osteoconductive and osteoinductive, thus supporting bone healing without further surgery (Saraf et al. 2010). Promising results have been achieved using bone substitutes or bone grafts mixed with bone substitutes and antibiotics. Among a broad variety of materials, calcium sulphate and calcium carbonate beads proved to be a suitable osteoconductive material for bone reconstruction (Wichelhaus et al. 2001; Evaniew et al. 2013; Roberts et al. 2013; CoraçaHuber et al. 2015).

Gentamicin sulphate (GS) salt is commonly used antibiotic for local application in orthopaedic surgery, for example mixed with PMMA cements. Gentamicin base (GB) consists of a mixture of gentamicin C1, C1a and $\mathrm{C} 2 \mathrm{a}+\mathrm{b}$. Gentamicin sulphate is highly water soluble. This substance can be used as a coating material for biomaterials and tissues by turning the water-soluble GS into a low-soluble gentamicin fatty acid salt (converting gentamicin sulphate to gentamicin palmitate; GP) (Kühn et al. 2003; Kuhn et al. 2008; Coraça-Huber et al. 2013a, b). Herafill ${ }^{\circledR}$ powder is used in the composition of bioabsorbable beads and is composed of calcium sulphate, calcium carbonate and glycerine tripalmitate as bonding additive. It contains $1 \%$ of GS corresponding to $2.5 \mathrm{~g}$ of GB. Herafill $^{\circledR}$ is also manufactured as granules to be used as a bone void filling material as well as an antibiotic carrier (Coraça-Huber et al. 2014).

In this study we evaluated two different preparations of femoral heads allografts as antibiotic carrier. Lyophilized bone chips and fresh frozen bone chips were mixed with gentamicin sulphate, gentamicin palmitate, vancomycin, calcium carbonate/calcium 
sulphate impregnated with gentamicin sulphate, and calcium carbonate/calcium sulphate bone substitute material impregnated with vancomycin. The efficacy of each preparation was measured by drug release tests and bacterial susceptibility using B. subtilis, S. aureus and methicillin-resistant Staphylococcus aureus.

\section{Materials and methods}

\section{Bone tissue}

Different preparation of femoral heads allografts obtained from living donors (telos $\mathrm{GmbH}$, Marburg, Germany and Tissue Bank, Charité-Medical University Berlin, Berlin, Germany) were used as antibiotic carrier. Two different preparations were tested: lyophilized bone chips (BChT) and fresh frozen bone chips (FF-BChT). All patients gave their written consent that the removed tissue was allowed to be used for research purposes.

\section{Antibiotic and reference substances}

Gentamicin sulphate (GS), gentamicin palmitate (GP), vancomycin $(\mathrm{V})$, calcium carbonate/calcium sulphate bone substitute material impregnated with 5 and $10 \%$ gentamicin sulphate (HeraG; Herafill ${ }^{\circledR}$ ) and calcium carbonate/calcium sulphate bone substitute material impregnated with 5 and $10 \%$ vancomycin hydrochloride $\left(\right.$ HeraV; Herafill ${ }^{\circledR}$ ) were used in this study. Polymethylmethacrylate beads impregnated with gentamicin sulfate (Heraeus PMMA Chain G30, Heraeus Medical GmbH, Wehrheim, Germany; approximately $4.5 \mathrm{mg}$ gentamicin per bead) and calcium carbonate/calcium sulfate bone substitute beads impregnated with gentamicin sulfate (Herafill ${ }^{\circledR}$ beads $G^{\circledR}$, Heraeus Medical GmbH, Wehrheim, Germany; 2.5 mg gentamicin per bead) were used as reference materials. Also, FF-BChT (telos GmbH, Marburg, Germany and Tissue Bank, Charité-Medical University Berlin, Berlin, Germany) samples were used as reference materials.

\section{Microorganisms}

Bacillus subtilis (Merck KGaA, Germany in Test Agar pH 8.0 Merck KGaA, Germany), Staphylococcus aureus ATCC 29213 (American Type Culture Collection, LGC Standards GmbH, Wesel, Germany) and methicillin-resistant Staphylococcus aureus MRSA DSM 46320 (Leibniz Institute DSMZ Deutsche Sammlung von Mikroorganismen und ZellkulturenGerman Collection of Microorganisms and Cell Cultures, Braunschweig, Germany) were used for antibiotic delivery and antibiotic susceptibility assays.

\section{Gentamicin base release}

To evaluate the release rate of antibiotics from allografts, the BChT samples were mixed with GS, GS + GP, V, HeraG, HeraV. The exactly concentration of each mixtures is detailed on Table 1 . The antibiotic release assay was carried out using phosphate-buffered saline (PBS) pH 7.4 (Sigma-Aldrich, Schnelldorf, Germany). For that, $3 \mathrm{ml}$ of PBS were added into each tube containing $1 \mathrm{~cm}^{3}$ of each BChT mixture. The tubes were vortexed for $1 \mathrm{~min}$ and placed on a shaker at $37{ }^{\circ} \mathrm{C}$. Daily, from 1 to 14 days, the elution medium was completely removed and fresh PBS was added. The removed elution was vortexed and stored at $-20{ }^{\circ} \mathrm{C}$ until the tests.

Bacillus subtilis assay for estimation of antibiotic release concentrations

Concentrations of the delivered antibiotic in the elution were determined by a conventional microbiological agar diffusion assay using Bacillus subtilis as the indicator strain already described by Coraça-Huber et al. (2015). Using a 6-mm diameter metal punch, a hole was made at the center of each $B$. subtilis agar plate into which $100 \mu \mathrm{L}$ of each collected elution or $100 \mu \mathrm{L}$ of 10-fold dilutions of each standard concentration was added. The plates containing the samples were incubated at $37{ }^{\circ} \mathrm{C}$ for $24 \mathrm{~h}$. After the incubation, the diameter of the zones of inhibition in centimeters $(\mathrm{cm})$ was measured for each plate with a ruler. The diameter was confirmed with a second measurement. The size of punched area was subtracted for the final measurement. The standard curve was obtained by logarithmic regression and used to predict the concentration of GB in each elution. This assay was carried out in triplicate.

Staphylococcus aureus and methicillin-resistant Staphylococcus aureus susceptibility tests

Staphylococcus aureus ATCC 29213 and methicillinresistant Staphylococcus aureus MRSA DSM 46320 
Table 1 Mixtures used for antibiotic delivery tests

Mixtures used for the antibiotic delivery assay

\begin{tabular}{|c|c|}
\hline Test groups & Concentration mixtures \\
\hline $\mathrm{BChT}+\mathrm{GS} / \mathrm{GP}(1.6 \% \mathrm{~GB})$ & $1 \mathrm{~g} \mathrm{BChT}+0.016 \mathrm{~g} \mathrm{~GB}(0.014 \mathrm{~g} \mathrm{GS})+0.016 \mathrm{~g} \mathrm{~GB}(0.04 \mathrm{~g} \mathrm{GP})$ \\
\hline BChT + GS/GP (3.2\% GB) & $1 \mathrm{~g} \mathrm{BChT}+0.032 \mathrm{~g} \mathrm{~GB}(0.028 \mathrm{~g} \mathrm{GS})+0.032 \mathrm{~g} \mathrm{~GB}(0.08 \mathrm{~g} \mathrm{GP})$ \\
\hline $\mathrm{BChT}+\mathrm{GS} / \mathrm{GP}(6.4 \% \mathrm{~GB})$ & $1 \mathrm{~g} \mathrm{BChT}+0.064 \mathrm{~g} \mathrm{~GB}(0.056 \mathrm{~g} \mathrm{GS})+0.064 \mathrm{~g} \mathrm{~GB}(0.16 \mathrm{~g} \mathrm{GP})$ \\
\hline BChT + HeraG $10 \%(1.6 \% \mathrm{~GB})$ & $1 \mathrm{~g} \mathrm{BChT}+0.016 \mathrm{~GB}(0.16 \mathrm{~g} \mathrm{GS})$ \\
\hline BChT + HeraG $10 \%(3.2 \% \mathrm{~GB})$ & $1 \mathrm{~g} \mathrm{BChT}+0.032 \mathrm{~GB}(0.32 \mathrm{~g} \mathrm{GS})$ \\
\hline $\mathrm{BChT}+$ HeraG $10 \%(6.4 \% \mathrm{~GB})$ & $1 \mathrm{~g} \mathrm{BChT}+0.064 \mathrm{~GB}(0.64 \mathrm{~g} \mathrm{GS})$ \\
\hline BChT + HeraG $5 \%(6.4 \% \mathrm{~GB})$ & $1 \mathrm{~g} \mathrm{BChT}+0.064(1.28 \mathrm{~g} \mathrm{GS})$ \\
\hline $\mathrm{BChT}+$ HeraV $10 \%(2 \% \mathrm{VB})$ & $1 \mathrm{~g} \mathrm{BChT}+0.02 \mathrm{~g} \mathrm{VB}(0.2 \mathrm{~g} \mathrm{~V})$ \\
\hline $\mathrm{BChT}+$ HeraV $10 \%(4 \% \mathrm{VB})$ & $1 \mathrm{~g} \mathrm{BChT}+0.04 \mathrm{~g} \mathrm{VB}(0.4 \mathrm{~g} \mathrm{~V})$ \\
\hline BCht + HeraV $10 \%(8 \%$ VB $)$ & $1 \mathrm{~g} \mathrm{BChT}+0.08 \mathrm{~g} \mathrm{VB}(0.8 \mathrm{~g} \mathrm{~V})$ \\
\hline BCht + HeraV $5 \%(8 \%$ VB $)$ & $1 \mathrm{~g} \mathrm{BChT}+0.08 \mathrm{~g} \mathrm{VB}(1.6 \mathrm{~g} \mathrm{~V})$ \\
\hline Reference groups & Concentration mixtures \\
\hline $\mathrm{BChT}+\mathrm{GS}$ & $1 \mathrm{~g} \mathrm{BChT}+1 \mathrm{~mL}$ (gentamicin $1 \mathrm{mg} / \mathrm{mL}$ ) (Witso et al. 2005) \\
\hline $\mathrm{BChT}+\mathrm{V}$ & $1 \mathrm{~g} \mathrm{BChT}+1 \mathrm{~mL}$ (vancomycin $1 \mathrm{mg} / \mathrm{mL}$ ) (Witso et al. 2005) \\
\hline PMMA beads & $\simeq 1 \mathrm{~g}$ gentamicin sulfate/bead \\
\hline Herafill beads & $2.5 \mathrm{mg}$ gentamicin sulfate/bead \\
\hline $\mathrm{FF}-\mathrm{BChT}+\mathrm{GS}+\mathrm{GP}(1.6 \% \mathrm{~GB})$ & $1 \mathrm{~g} \mathrm{FF}-\mathrm{BChT}+0.016 \mathrm{~g} \mathrm{~GB}(0.014 \mathrm{~g} \mathrm{GS})+0.016 \mathrm{~g} \mathrm{~GB}(0.04 \mathrm{~g} \mathrm{GP})$ \\
\hline FF-BChT + GS/GP (3.2 \% GB) & 1 g FF-BChT +0.032 g GB(0.028 g GS $)+0.032$ g GB $(0.08$ g GP $)$ \\
\hline $\mathrm{FF}-\mathrm{BChT}+\mathrm{GS} / \mathrm{GP}+(6.4 \% \mathrm{~GB})$ & $1 \mathrm{gFF}-\mathrm{BChT}+0.064 \mathrm{~g} \mathrm{~GB}(0.056 \mathrm{~g} \mathrm{GS})+0.064 \mathrm{~g} \mathrm{~GB}(0.16 \mathrm{~g} \mathrm{GP})$ \\
\hline
\end{tabular}

Test groups: lyophilized bone chips mixed with gentamicin sulfate and gentamicin palmitate powder (BChT + GS/GP); gentamicin base powder (GB); lyophilized bone chips mixed with calcium carbonate/calcium sulphate impregnated with gentamicin sulphate powder $(\mathrm{BChT}+\mathrm{HeraG})$; lyophilized bone chips mixed with calcium carbonate/calcium sulphate granulate impregnated with vancomycin (BChT + HeraV); Reference groups: lyophilized bone chips impregnated with gentamicin sulphate by immersion $(\mathrm{BChT}+\mathrm{GS})$ (Witso et al. 2005); lyophilized bone chips impregnated with vancomycin by immersion (BChT $+\mathrm{V})$ (Witso et al. 2005) polymethylmethacrylate beads impregnated with gentamicin sulfate (PMMA beads); calcium carbonate/calcium sulfate bone substitute beads impregnated with gentamicin sulfate (Herafill beads); fresh frozen bone chips mixed with gentamicin sulfate and gentamicin palmitate (FF-BChT + GS/GP). The mixtures were kept for $24 \mathrm{~h}$ prior de addition of PBS for the elution tests

suspensions at $2 \times 10^{5}$ cells $(0.5$ McFarland) were prepared and $10 \mu \mathrm{L}$ were inoculated using MüllerHinton agar plates. With a 6-mm diameter metal punch, a hole was made on the center of each plate where $100 \mu \mathrm{L}$ of each sample was added. The plates were incubated at $37{ }^{\circ} \mathrm{C}$ for $24 \mathrm{~h}$. After $24 \mathrm{~h}$, the zones of inhibition were measured on each plate with a ruler. The diameter was confirmed with a second measurement. The size of the punched area was subtracted for the final measurement. These tests were carried out in triplicate.

\section{Statistical analysis}

Statistical evaluation was carried out to detect differences between the delivery rate and susceptibility tests between the samples tested. To evaluate the differences between the samples taking into consideration the elution concentration along the time Twoway ANOVA with Bonferroni's multiple comparisons test was applied. To detect the cumulative differences and susceptibility of microorganisms between the mixtures One-way ANOVA with Bonferroni's multiple comparisons test was carried out.

\section{Results}

Bacillus subtilis assay for estimation of antibiotic release concentrations

Taking into consideration the release of antibiotics from the BChT and PMMA and Herafill beads we 
could observe that the BChT + GS and PMMA beads showed a significant higher delivery rate in comparison with $\mathrm{BChT}+\mathrm{V}$ and Herafill beads. PMMA beads were the only material that allowed delivery of antibiotic at least until the 14th day. However, the significant release was observed only until the 5th day $(p<0.0001$; Fig. 1a). The antibiotic delivery rate from fresh frozen samples followed the concentration of GS + GP from each group where FF$\mathrm{BChT}+\mathrm{GS}+\mathrm{GP} 6.4 \%$ showed significant higher concentration in comparison with FF$\mathrm{BChT}+\mathrm{GS}+\mathrm{GP} 1.6$ and $3.2 \%$. The highest concentration were detected until the 5th day of elution $(p<0.05$; Fig. 1b). The antibiotic concentration in the elution of BChT + GS + GP also followed the mixture concentration. Here $\mathrm{BChT}+\mathrm{GS}+\mathrm{GP}$ $6.4 \%$ showed higher antibiotic release when compared to $\mathrm{BChT}+\mathrm{GS}+\mathrm{GP} 1.6$ and $3.2 \%$. The highest delivery was detected only until the 3rd elution day ( $p<0.001$; Fig. 2a). The antibiotic delivery from the BChT mixed with HeraG also followed the concentration of the mixtures made prior the elution tests. Here BChT + HeraG $10 \%$ (6.4\% GB) and $\mathrm{BChT}+\mathrm{HeraG} 5 \%(6.4 \% \mathrm{~GB})$ showed no significant differences between the concentrations of antibiotic released. The two groups showed the highest levels of antibiotic being released until the 4th elution day. Although, BChT + HeraG $10 \%(6.4 \% \mathrm{~GB})$ and BChT + HeraG $5 \%(6.4 \% \mathrm{~GB})$ delivery significant different concentration $(p<0.05)$ of the antibiotic in comparison to BChT + HeraG $10 \%(1.6 \% \mathrm{~GB})$ and $\mathrm{BChT}+$ HeraG $10 \%(3.2 \% \mathrm{~GB})$. In these two groups the highest delivery was detected until the 2nd elution day (Fig. 2b). A similar pathway could be observed between the groups of BChT mixed with HeraV. Here BChT + HeraV $(8 \%$ VB $)$ and $\mathrm{BChT}+\mathrm{HeraV} 5 \%(8 \% \mathrm{VB})$ showed very high concentration release in comparison with $\mathrm{BChT}+\mathrm{HeraV} 10 \%(2 \% \mathrm{VB})$ and $\mathrm{BChT}+\mathrm{HeraV}$ $10 \%$ (4 \% VB). However BChT + HeraV $10 \%(8 \%$ $\mathrm{VB})$ showed significant higher delivery $(p<0.05)$ in comparison with BChT + HeraV $10 \%(2 \% \mathrm{VB})$ and in comparison with $\mathrm{BChT}+\mathrm{HeraV} 10 \%(2 \% \mathrm{VB})$ and $\mathrm{BChT}+\mathrm{HeraV} 10 \%$ (4\% VB; $p<0.0001)$. Also here, the highest delivery rate was detected until the 3rd and 4th elution day (Fig. 2c).
Staphylococcus aureus and methicillin-resistant Staphylococcus aureus susceptibility tests

Here we calculated the cumulative values from all time intervals to show the mixture with better antibacterial effect. Within the group of reference samples, against $S$. aureus, the best activity was observed by PMMA beads and all the FF$\mathrm{BChT}+\mathrm{GS}+\mathrm{GP}$. Also BChT + GS showed high efficacy. These mixtures showed significant higher activity $(p<0.05)$ in comparison with the other mixtures. BChT $+\mathrm{V}$ and Herafill beads showed less activity and no significant difference between each other (Fig. 3a). Similar results were obtained with the samples tested against MRSA (Fig. 3b). The cumulative results for the susceptibility tests against $S$. aureus and MRSA for the BChT mixed with GS + GP, HeraG and HeraV, showed that the activity of BChT mixed with GS + GP was significantly higher in comparison with BChT mixed with HeraG and HeraV ( $p<0.05$; Fig. $4 \mathrm{a}, \mathrm{b}$ ). Besides the cumulative results for the susceptibility tests against $S$. aureus and MRSA, the measurement of the zone of inhibition is also presented for each time interval. In the reference groups we can also observe the highest efficacy of PMMA beads and BChT + GS against $S$. aureus and MRSA in comparison with BChT $+\mathrm{V}$ and Herafill beads (Fig. 5a, b). For the fresh frozen samples, besides the difference in antibiotic concentration, the three groups (FF + BChT + GS + GP $1.6 \%$, $\mathrm{FF}+\mathrm{BChT}+\mathrm{GS}+\mathrm{GP} 3.2 \%, \quad \mathrm{FF}+\mathrm{BChT}+$ GS + GP $6.4 \%$ ) showed similar effect against the microorganisms showing its activity until the 14th elution day (Fig. 5c, d). For the samples of the test group, the mixture that most efficiently delivered the antibiotic substances until the last day was $\mathrm{BChT}+\mathrm{GS}+\mathrm{GP}$, for all concentration of gentamicin base used. Here we can see that even at the last day, all the concentration reached a zone of inhibition of approximately $2 \mathrm{~cm}$. The efficiency of $\mathrm{BChT}+\mathrm{GS}+\mathrm{GP}$ was similar against $S$. aureus and MRSA. The mixtures of BChT with HeraG showed high antimicrobial activity until the end of the first week for $S$. aureus and MRSA. The mixture of BChT with HeraV showed less activity against the microorganisms in comparison with $\mathrm{BChT}+$ 
Fig. 1 Reference groups: antibiotic release concentrations obtained from Bacillus subtilis assay. a Lyophilized bone chips impregnated with gentamicin sulphate by immersion $(1 \mathrm{mg} / \mathrm{mL}$; BChT + GS); lyophilized bone chips impregnated with vancomycin sulphate by immersion $(1 \mathrm{mg} / \mathrm{mL}$; $\mathrm{BChT}+\mathrm{V})$ polymethylmethacrylate beads impregnated with gentamicin sulfate (PMMA beads); calcium carbonate/calcium sulfate bone substitute beads impregnated with gentamicin sulfate (Herafill beads); $\mathbf{b}$ fresh-frozen bone fragments mixed with gentamicin sulfate and gentamicin palmitate $1.6 \%$ of gentamicin base (FF-

$\mathrm{BChT}+\mathrm{GS}+\mathrm{GP} 1.6 \%$ ) fresh-frozen bone fragments mixed with gentamicin sulfate and gentamicin palmitate $3.2 \%$ of gentamicin base (FF$\mathrm{BChT}+\mathrm{GS}+\mathrm{GP} 3.2 \%$ ); fresh-frozen bone fragments mixed with gentamicin sulfate and gentamicin palmitate $6.4 \%$ of gentamicin base $(\mathrm{FF}+\mathrm{BChT}+\mathrm{GS}+\mathrm{GP}$ $6.4 \%$ )
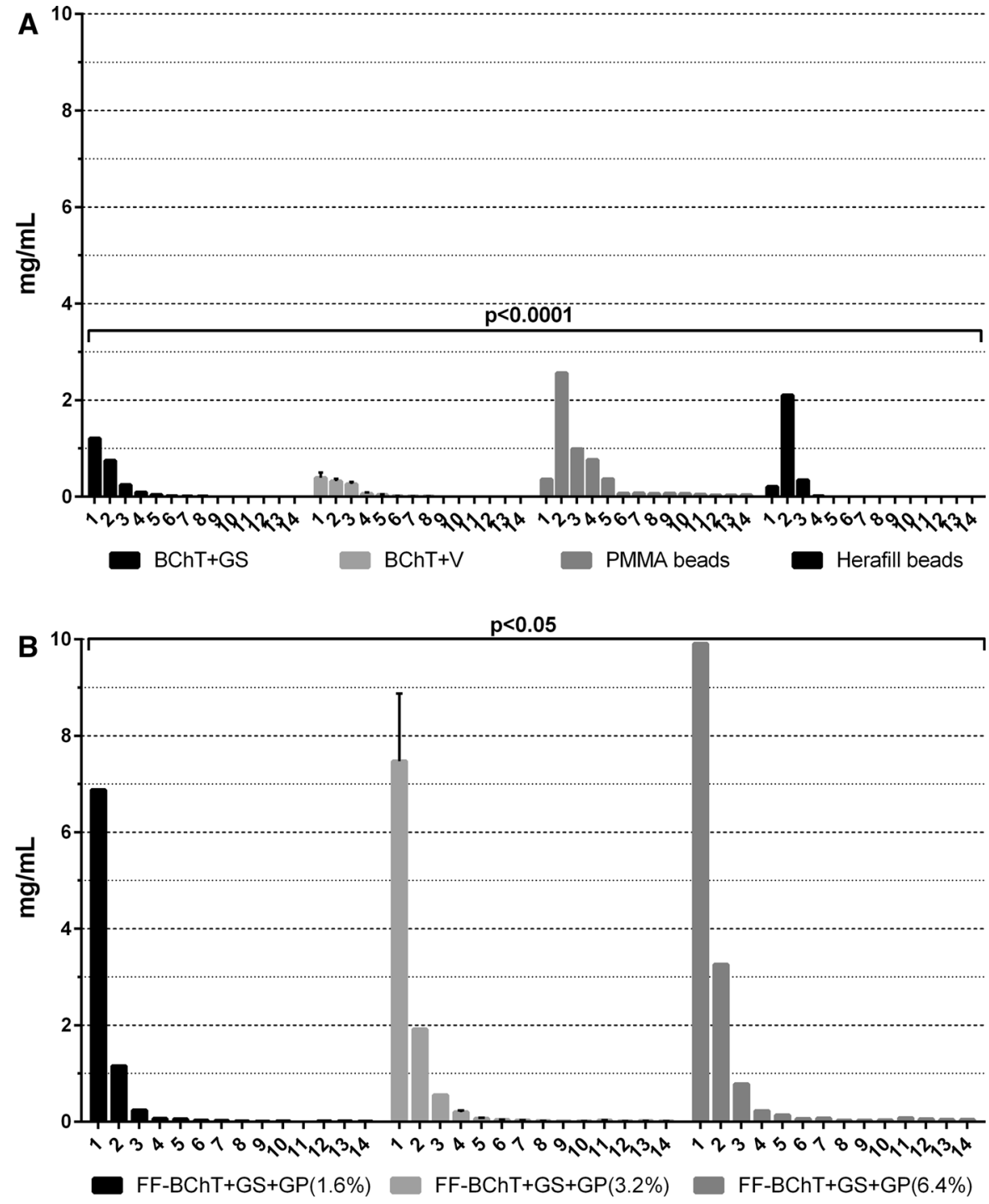

GS + GP, however, this activity could be observed until the 10th elution day (Fig. 6).

\section{Discussion}

Once an infection is established, the removal of implanted devices is necessary for a proper treatment (Zimmerli et al. 2004; Frommelt 2006). Biomaterialmediated infections are resistant to antibiotic treatment even at high doses (Gristina 1987). Only early infections might be managed with systemic antibiotic therapy (Zimmerli et al. 2004; Frommelt 2006). Surgical debridement removing all suspicious tissue is essential to achieve control of infection and good long-term results (Frommelt 2006). Early detection of infection and aggressive treatment has a high eradication rate since only $64 \%$ of all infections occurred within the first 12 months of primary surgery (Phillips et al. 2006).

In this study we evaluated two different preparations of femoral heads allografts as antibiotic carrier. Lyophilized and fresh frozen bone chips. Lyophilisation of bone allografts can be conducted under complete screening of donors, does not use any chemical agents for preparation and can help decrease the contaminants. The lyophilisation process of bone causes only a small reduction of pull-out force which 
Fig. 2 Test groups: antibiotic release concentrations obtained from Bacillus subtilis assay. a Lyophilized bone chips mixed with gentamicin sulfate and gentamicin palmitate $1.6 \%$ of gentamicin base $(\mathrm{BChT}+\mathrm{GS}+\mathrm{GP}$ $1.6 \%$ ); lyophilized bone chips mixed with gentamicin sulfate and gentamicin palmitate $3.2 \%$ of gentamicin base $(\mathrm{BChT}+\mathrm{GS}+\mathrm{GP}$ $3.2 \%$ ); lyophilized bone chips mixed with gentamicin sulfate and gentamicin palmitate $6.4 \%$ of gentamicin base $(\mathrm{BChT}+\mathrm{GS}+\mathrm{GP}$ $6.4 \%)$; b lyophilized bone chips mixed with HerafillG $10 \%$ with $1.6 \%$ gentamicin base (BChT + HeraG $10 \%-1.6 \% \mathrm{~GB})$; lyophilized bone chips mixed with HerafillG $10 \%$ with $3.2 \%$ gentamicin base (BChT + HeraG $10 \%$ -

$3.2 \% \mathrm{~GB}$ ); lyophilized bone chips mixed with HerafillG $10 \%$ with $6.4 \%$ gentamicin base $(\mathrm{BChT}+\mathrm{HeraG}$ $10 \%-6.4 \% \mathrm{~GB})$; lyophilized bone chips mixed with HerafillG $5 \%$ with $6.4 \%$ gentamicin base (BChT + HeraG $5 \%$ $6.4 \% \mathrm{~GB})$; c lyophilized bone chips mixed with HerafillV $10 \%$ with $2 \%$ vancomycin base (BChT + HeraV $10 \%$ $2 \% \mathrm{~GB}$ ); lyophilized bone chips mixed with Herafill V $10 \%$ with $4 \%$ vancomycin base (BChT + HeraV $10 \%-4 \% \mathrm{~GB})$; lyophilized bone chips mixed with HerafillV $10 \%$ with $8 \%$ vancomycin base (BChT + HeraV $10 \%$ $8 \% \mathrm{~GB})$; lyophilized bone chips mixed with HerafillV $10 \%$ with $8 \%$ vancomycin base $(\mathrm{BChT}+\mathrm{HeraV}$ $5 \%-8 \% \mathrm{~GB}$ )
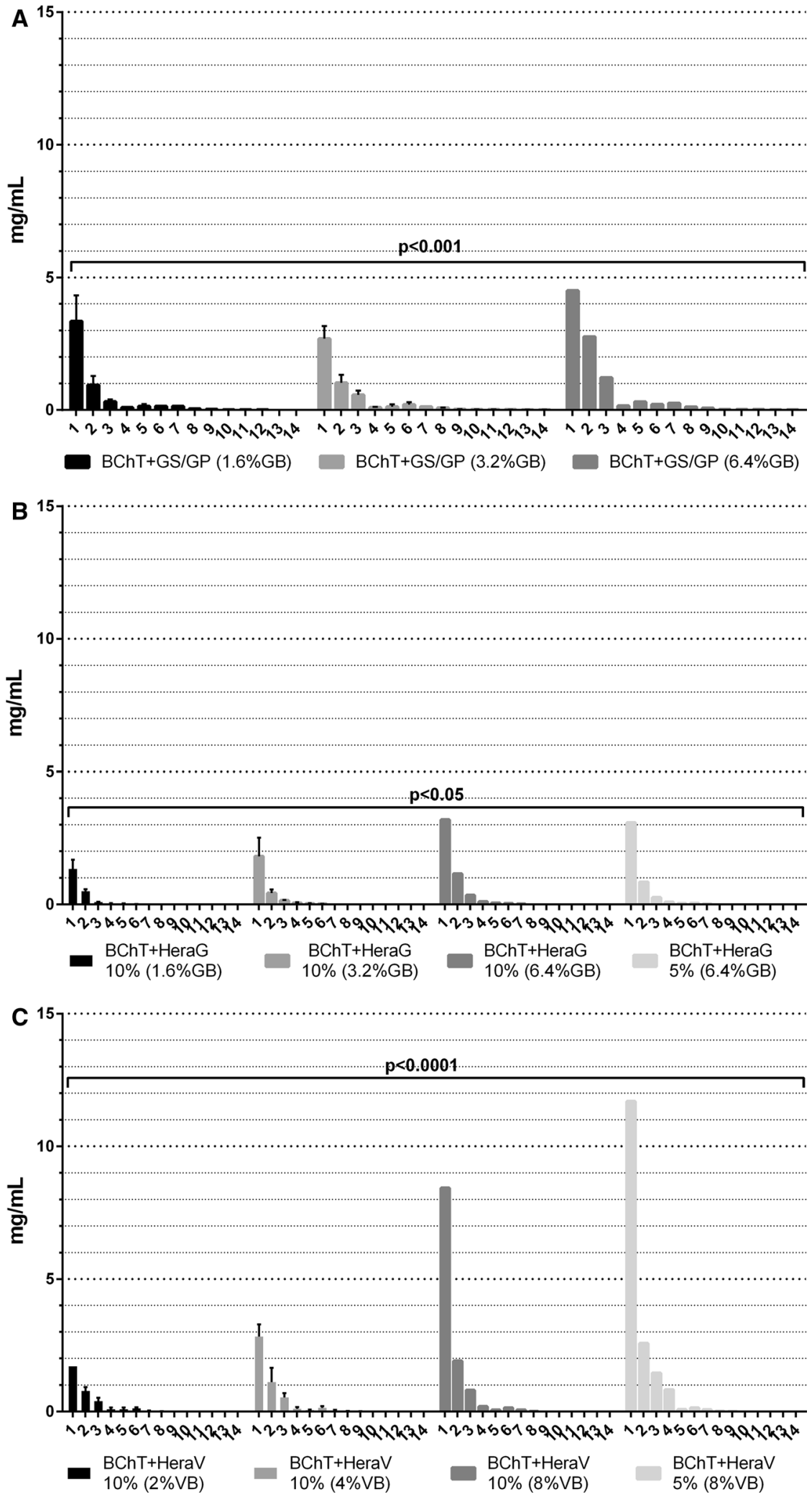


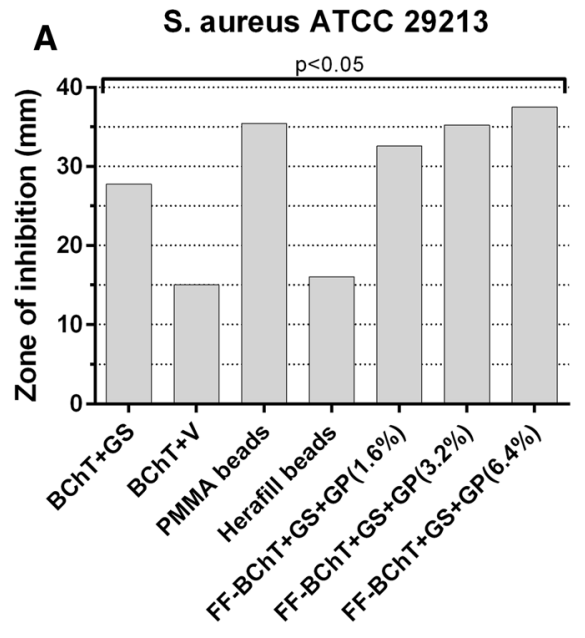

Fig. 3 Cumulative results for susceptibility tests of antibiotic released against a $S$. aureus ATCC 29213 and b MRSA DSM 46320. Reference groups: Lyophilized bone chips impregnated with gentamicin sulphate by immersion $(1 \mathrm{mg} / \mathrm{mL}$; BChT + GS); lyophilized bone chips impregnated with vancomycin sulphate by immersion $(1 \mathrm{mg} / \mathrm{mL} ; \quad$ BChT $+\mathrm{V})$ polymethylmethacrylate beads impregnated with gentamicin sulfate (PMMA beads); calcium carbonate/calcium sulfate bone substitute beads impregnated with gentamicin sulfate (Herafill

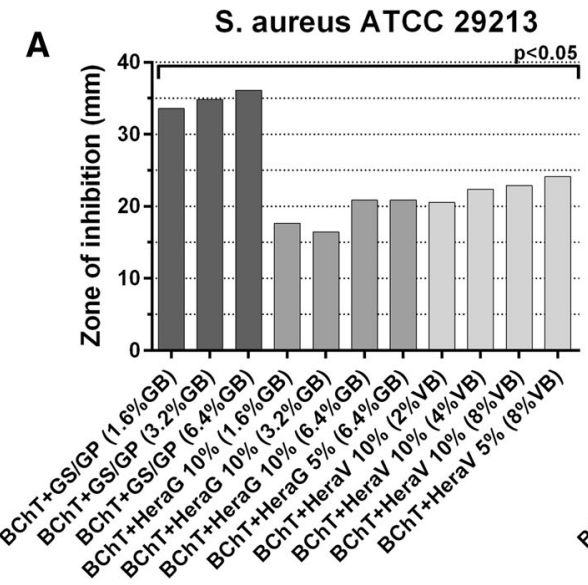

Fig. 4 Cumulative results for susceptibility tests of antibiotic released against a $S$. aureus ATCC 29213 and b MRSA DSM 46320. Test groups: lyophilized bone chips mixed with gentamicin sulfate and gentamicin palmitate $1.6 \%$ of gentamicin base (BChT + GS + GP 1.6\%); lyophilized bone chips mixed with gentamicin sulfate and gentamicin palmitate $3.2 \%$ of gentamicin base (BChT + GS + GP $3.2 \%$ ); lyophilized bone chips mixed with gentamicin sulfate and gentamicin palmitate $6.4 \%$ of gentamicin base (BChT + GS + GP $6.4 \%$ ); lyophilized bone chips mixed with HerafillG $10 \%$ with $1.6 \%$ gentamicin base (BChT + HeraG $10 \%$ $1.6 \% \mathrm{~GB})$; lyophilized bone chips mixed with HerafillG $10 \%$ with $3.2 \%$ gentamicin base (BChT + HeraG $10 \%-$

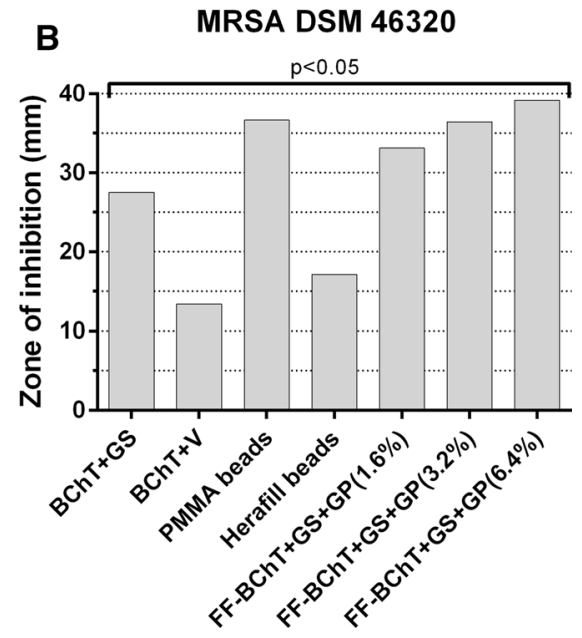

beads); fresh-frozen bone fragments mixed with gentamicin sulfate and gentamicin palmitate $1.6 \%$ of gentamicin base (FF$\mathrm{BChT}+\mathrm{GS}+\mathrm{GP} 1.6 \%$ ); fresh-frozen bone fragments mixed with gentamicin sulfate and gentamicin palmitate $3.2 \%$ of gentamicin base (FF-BChT + GS + GP $3.2 \%$ ); fresh-frozen bone fragments mixed with gentamicin sulfate and gentamicin palmitate $6.4 \%$ of gentamicin base $(\mathrm{FF}+\mathrm{BChT}+\mathrm{GS}+\mathrm{GP}$ $6.4 \%$ )

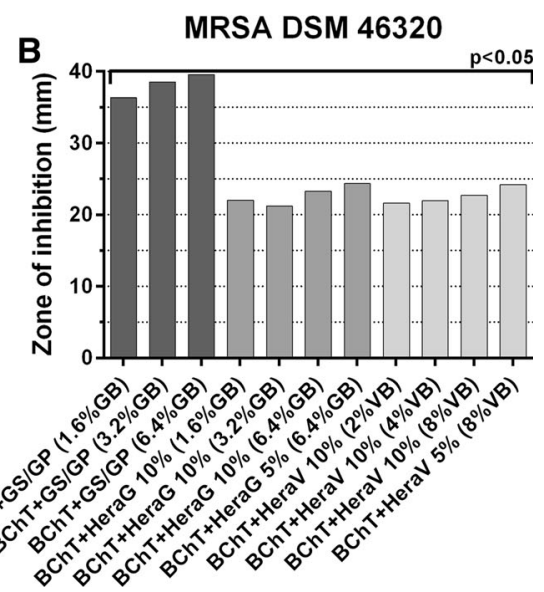

$3.2 \% \mathrm{~GB})$; lyophilized bone chips mixed with HerafillG $10 \%$ with $6.4 \%$ gentamicin base (BChT + HeraG $10 \%-$ $6.4 \% \mathrm{~GB})$; lyophilized bone chips mixed with HerafillG $5 \%$ with $6.4 \%$ gentamicin base (BChT + HeraG $5 \%-6.4 \% \mathrm{~GB})$; lyophilized bone chips mixed with HerafillV $10 \%$ with $2 \%$ vancomycin base (BChT + HeraV $10 \%-2 \% \mathrm{~GB}$ ); lyophilized bone chips mixed with Herafill V $10 \%$ with $4 \%$ vancomycin base (BChT + HeraV10\%-4\%GB); lyophilized bone chips mixed with HerafillV $10 \%$ with $8 \%$ vancomycin base (BChT + HeraV $10 \%-8 \% \mathrm{~GB})$; lyophilized bone chips mixed with HerafillV $10 \%$ with $8 \%$ vancomycin base (BChT + HeraV $5 \%-8 \% \mathrm{~GB})$ 


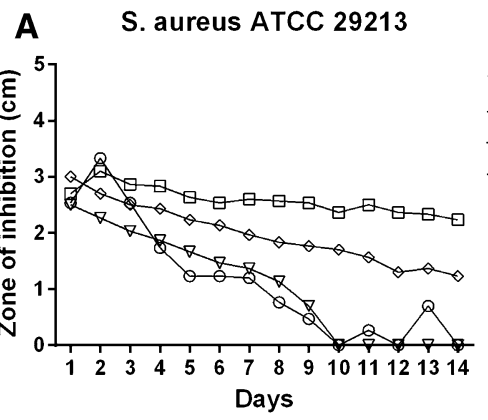

$\multimap$ Herafill beads

๑ PMMA beads

$\rightarrow \mathrm{BChT}+\mathrm{V}$

$\diamond \mathrm{BChT+GS}$
C

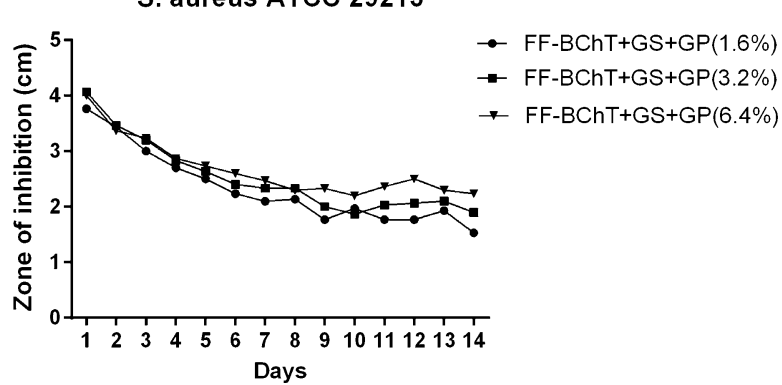

Fig. 5 Susceptibility tests of antibiotic released against a $S$. aureus ATCC 29213 and b MRSA DSM 46320. Reference groups: a, b lyophilized bone chips impregnated with gentamicin sulphate by immersion ( $1 \mathrm{mg} / \mathrm{mL}$; BChT + GS); lyophilized bone chips impregnated with vancomycin sulphate by immersion $(1 \mathrm{mg} / \mathrm{mL}$; BChT $+\mathrm{V})$ polymethylmethacrylate beads impregnated with gentamicin sulfate (PMMA beads); calcium carbonate/calcium sulfate bone substitute beads impregnated with gentamicin sulfate (Herafill beads); c,

is not relevant regarding impaction of bone allograft in revision surgery arthroplasty (Folsch et al. 2012).

The allografts in this study were mixed with gentamicin sulphate, gentamicin palmitate, vancomycin, calcium carbonate/calcium sulphate impregnated with gentamicin sulphate, and calcium carbonate/calcium sulphate bone substitute material $\left(\right.$ Herafill $^{\circledR}$ ) impregnated with vancomycin. Local administration of antibiotics delivered from cement was introduced in orthopaedic surgeries in 1970 (Buchholz and Engelbrecht 1970). Cancellous bone grafts were reported as antibiotic delivery system and bone grafts are commonly used to augment bone defects (Lindsey et al. 1993; Goldberg 2000). Impacted morselized allograft bone is a recognized method to obtain additional support for arthroplasty in revision surgery (Toms et al. 2004; Oakes and Cabanela 2006; Barckman et al. 2014). Antibioticsupplemented impacted bone grafts improve outcome in revision surgery of infected endoprostheses
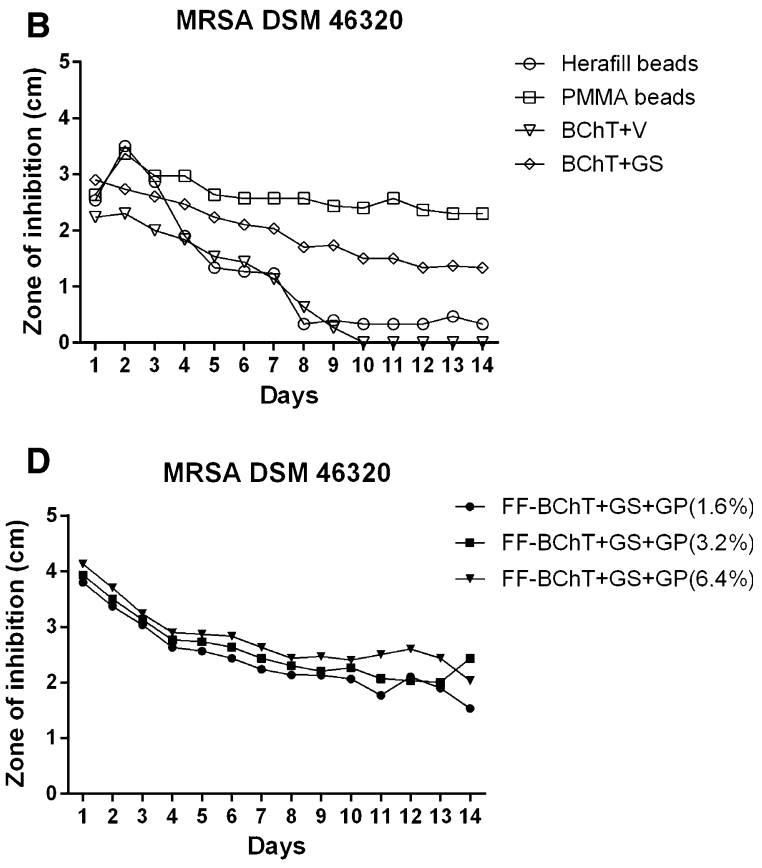

d fresh-frozen bone fragments mixed with gentamicin sulfate and gentamicin palmitate $1.6 \%$ of gentamicin base (FF$\mathrm{BChT}+\mathrm{GS}+\mathrm{GP} 1.6 \%$ ); fresh-frozen bone fragments mixed with gentamicin sulfate and gentamicin palmitate $3.2 \%$ of gentamicin base (FF-BChT + GS + GP $3.2 \%$ ); fresh-frozen bone fragments mixed with gentamicin sulfate and gentamicin palmitate $6.4 \%$ of gentamicin base $(\mathrm{FF}+\mathrm{BChT}+\mathrm{GS}+\mathrm{GP}$ $6.4 \%$ )

since systemic applied antibiotics do not reach sufficient concentrations around the grafts (Buttaro et al. 2005; Winkler et al. 2006; Barckman et al. 2014). Surgical revision of arthroplasty without cement but augmentation with bone grafts improves the bone stock and might be beneficial for the longevity of the implant and further revision surgery since the number of cementless primary joint replacements is increasing in many countries. Antibiotic-loading of bone grafts seems appropriate to deliver adequate local concentrations similar to PMMA and even higher initial release within $24 \mathrm{~h}$. Good restoration of bone stock and low infection rate after revision of total hip replacements was shown for vancomycin-loaded impacted bone allograft (Buttaro et al. 2005; Winkler et al. 2006) since in vitro studies have shown the ability of bone grafts to deliver antibiotics (Witso et al. 2005; CoraçaHuber et al. 2013a, b; Barckman et al. 2014; CoraçaHuber et al. 2015). 

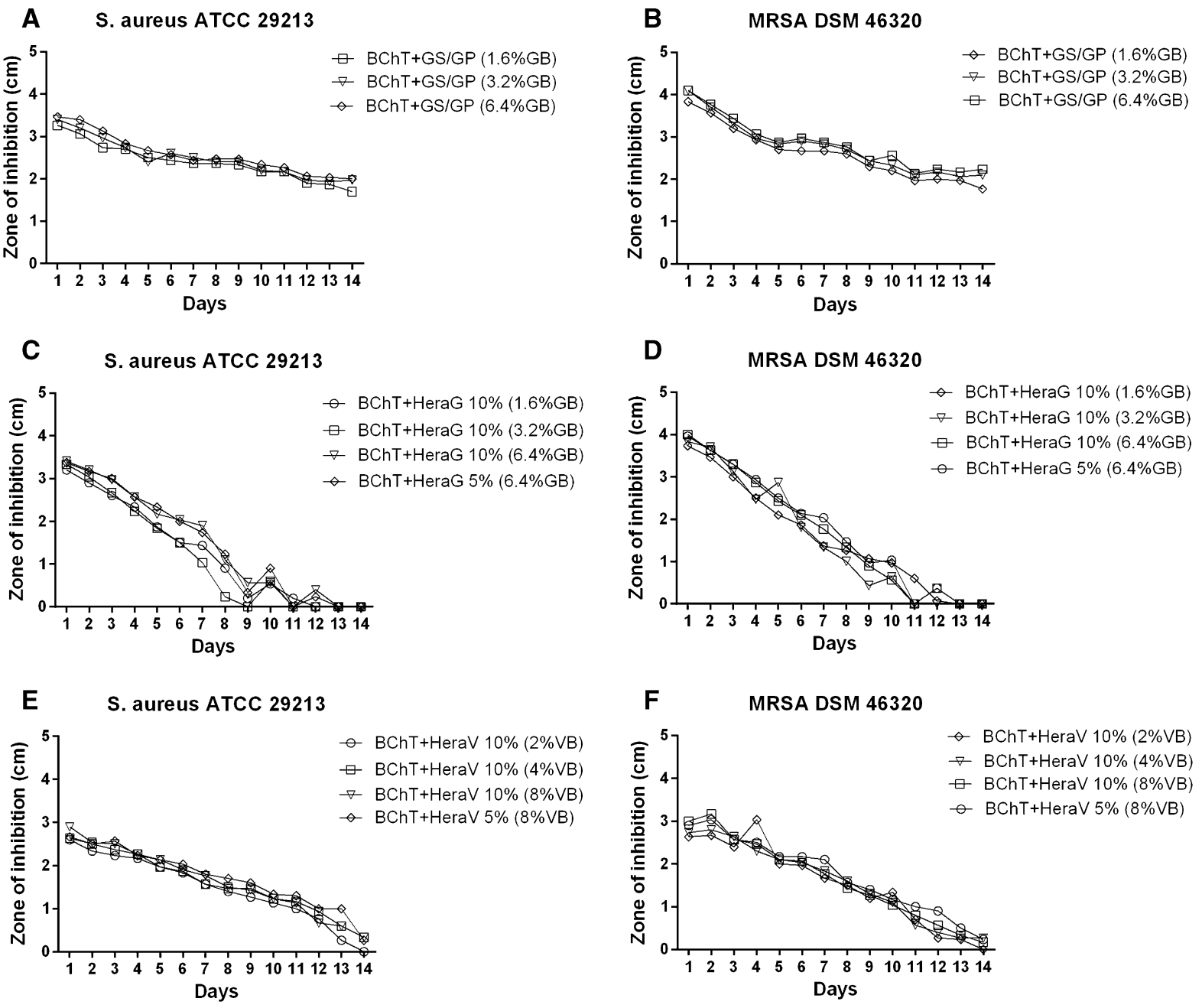

Fig. 6 Susceptibility tests of antibiotic released against (a, c, e) S. aureus ATCC 29213 and (b, d, f) MRSA DSM 46320. Test groups: a, b lyophilized bone chips mixed with gentamicin sulfate and gentamicin palmitate $1.6 \%$ of gentamicin base $(\mathrm{BChT}+\mathrm{GS}+\mathrm{GP} 1.6 \%)$; lyophilized bone chips mixed with gentamicin sulfate and gentamicin palmitate $3.2 \%$ of gentamicin base (BChT + GS + GP $3.2 \%$ ); lyophilized bone chips mixed with gentamicin sulfate and gentamicin palmitate $6.4 \%$ of gentamicin base (BChT + GS + GP $6.4 \%$ ); c, d lyophilized bone chips mixed with HerafillG $10 \%$ with $1.6 \%$ gentamicin base (BChT + HeraG $10 \%-1.6 \% \mathrm{~GB})$; lyophilized bone chips mixed with HerafillG $10 \%$ with $3.2 \%$ gentamicin base $(\mathrm{BChT}+$ HeraG $10 \%-3.2 \% \mathrm{~GB})$; lyophilized bone chips

The mixing of bone allografts with antibiotic salts in this study was carried out manually. As this procedure can be easily applied, we affirm that this is a suitable method for an operation room. As we used as one of the reference tests, some authors first dilute the antibiotic powder in a saline solution and then soak

mixed with HerafillG $10 \%$ with $6.4 \%$ gentamicin base (BChT + HeraG $10 \%-6.4 \% \mathrm{~GB})$; lyophilized bone chips mixed with HerafillG $5 \%$ with $6.4 \%$ gentamicin base $(\mathrm{BChT}+\mathrm{HeraG} 5 \%-6.4 \% \mathrm{~GB})$; e, f lyophilized bone chips mixed with HerafillV $10 \%$ with $2 \%$ vancomycin base $(\mathrm{BChT}+\mathrm{HeraV} 10 \%-2 \% \mathrm{~GB}) ;$ lyophilized bone chips mixed with Herafill V $10 \%$ with $4 \%$ vancomycin base $(\mathrm{BChT}+\mathrm{HeraV10} \%-4 \% \mathrm{~GB}) ;$ lyophilized bone chips mixed with HerafillV $10 \%$ with $8 \%$ vancomycin base $(\mathrm{BChT}+\mathrm{HeraV} 10 \%-8 \% \mathrm{~GB})$; lyophilized bone chips mixed with Herafillv $10 \%$ with $8 \%$ vancomycin base $(\mathrm{BChT}+$ HeraV $5 \%-8 \% \mathrm{~GB})$

the bone grafts in this solution before use (Winkler et al. 2000; Witso et al. 2005). We believe that this is an efficient method for bone chips incorporation with antibiotics since the tissue would act as a sponge absorbing the solution. According to these authors, that could also be an alternative for long-term storage 
of the grafts with antibiotic solutions. However, according to Sorger et al., the preservation of the grafts for up to $100 \mathrm{~h}$ in an antibiotic solution might influence the mechanical stability of the bone (Sorger et al. 2001). Based on Parrish et al. (1973), mechanical testing of osteochondral and structural allografts impregnated with antibiotics in solutions should be performed before this option is taken into clinical use.

In this study, drug concentrations were determined using a conventional microbiological agar well diffusion assay with Bacillus subtilis as indicator strain (Stevens et al. 2005; Witso et al. 2005). Because of the hydrophobic profile of GP which does not allow the obtainment of a homogeneous elution, we suggest this method for the concentration estimation instead of spectrometry techniques which could not show accurate results in these conditions. Due to its hydrophobic profile, it is expected that the GP coats not only the bone tissue but also the fat around the BCh (fresh frozen samples), which could increase the adsorption areas of the carrier. In this study, samples coated with GS + GP showed higher and longer release rates compared to the other substances. This could be due to its hydrophobic profile and affinity with the graft's fat tissue in some cases. Therefore, it could be an advantage of the combination of two the gentamicin salts (GS + GP), comparing with pure or other hydrophilic drugs that its concentrations are kept at homogeneous and constant rates. This could improve the protection of the bone grafts against infections for longer periods.

For the bacterial susceptibility, we tested the eluted substances against $S$. aureus and methicillin-resistant Staphylococcus aureus in this study. A range of bacterial species have been implicated in bone and joint infections, although staphylococcal species have been consistently shown to be the most common causative agents, representing approximately $75 \%$ of all strains. Among the staphylococci, Staphylococcus aureus remains a frequently isolated pathogen, causing $30-35 \%$ of all orthopaedic implant related infections (Arciola et al. 2005; Schäfer et al. 2008; Esteban et al. 2010; Montanaro et al. 2011; Schwotzer et al. 2014) especially methicillin-resistant $S$ aureus (MRSA) (Parvizi et al. 2009).

PMMA beads showed a constant delivery of gentamicin within 14 days with a peak release at day
2 since lyophilized allogeneic bone revealed a constant decline of delivery both providing an inhibition of S. aureus and MRSA after 2 weeks. Herafill ${ }^{\circledR}$ beads did not deliver antibiotics longer than day nine and Herafill $^{\circledR}$ and PMMA had a high peak release at day two compared with lyophilized allogeneic bone. Besides the positive results with PMMA in this study and the fact that PMMA is the gold standard biomaterial for local delivery of antibiotics, the efficacy of this material bears many limitations. Such shortcomings include limited antibiotic release, incompatibility with many antimicrobial agents, and the need for follow-up surgeries to remove the non-biodegradable cement before surgical reconstruction of the lost bone (Inzana et al. 2016). Herafill ${ }^{\circledR}$ on the other hand could be used as adjuvant in the bone impacting surgeries once it offers the mechanical stability and capacity of antibiotic local delivery. The capacity of bone grafts to act as gentamicin carriers once mixed with Herafill ${ }^{\circledR}$ granules has been confirmed by Coraça-Huber et al. The combination of the Herafill ${ }^{\circledR}$ granules in different sizes with two gentamicin salts (GS + GP) showed equivalent efficacy against $S$. aureus and $S$. epidermidis (Coraça-Huber et al. 2015).

The release of gentamicin from lyophilized allogeneic bone was similar to the release rate from fresh frozen bone during all the experimental time. That fact might be related to the similar porosity and microstructure of the bone chips (Witso et al. 2002). The release of gentamicin from lyophilized and fresh frozen bone was high in the first and second delivery day, decreasing and keeping a low rate until the end of the second week. Similar pathway for the delivery of antibiotic from bone samples was observed and described by Buttaro et al. 2005 and Winkler et al. 2008 where high initial release of antibiotics for cancellous bone was detected as well.

The release of vancomycin from lyophilized bone was effective against $S$. aureus until the 9th release day and MRSA only until 7th release day. Better results were observed by the release vancomycin from lyophilized bone mixed with Herafill ${ }^{\circledR}$. Here Herafill ${ }^{\circledR}$ mixed with vancomycin showed effect against $S$. aureus until day the 14th release day ( $8 \% \mathrm{VB})$ and MRSA until the 13th release day ( $8 \% \mathrm{VB})$. Witso et al. also showed the total elution time for vancomycin of 26-32 days in one of his studies using 
human cancellous bone as bone carrier (Witso et al. 2002). Witso did not describe a difference of release of vancomycin depending on the degree of morselizing of cancellous bone. Lyophilized bone mixed with Herafill ${ }^{\circledR} \mathrm{G}$ (up to $6.4 \% \mathrm{~GB}$ ) releases effective rates of antibiotics against $S$. aureus until 8th day and MRSA until 9th day.

In conclusion, lyophilized and fresh frozen bone chips showed a release rate of GB from 10 to $0.3 \mathrm{mg} /$ $\mathrm{mL}$ from 1 st to 4 th day (FF-BChT) and from 4 to $0.4 \mathrm{mg} / \mathrm{mL}$ from $1 \mathrm{st}$ to $3 \mathrm{rd}$ day. Although it is a low concentration of gentamicin, based on the literature this amount would be enough to reach the minimal inhibitory concentration (MIC) required for killing $S$. aureus in planktonic form (Alt et al. 2004; CoraçaHuber et al. 2012a). In this way, during the period of 7 days after implantation, the surgical site would be protected against bacterial infection. Until the end of 14 days, the release was low but still efficient to reduce bacteria counts. To maximize the delivery and protection against infection, higher concentration could be loaded to the bone allografts prior implantation.

\section{Conclusion}

Lyophilized and fresh frozen bone allografts once used as antibiotic carrier, provide efficient release concentration to inhibit bacterial growth in vitro. The protection of the grafts up to two weeks depending on the amount of antibiotic loaded and a combination of hydrophilic and hydrophobic antibiotics (e.g. gentamicin sulfate and gentamicin palmitate) are recommendable. The use of lyophilized and fresh frozen bone allografts as antibiotic carriers is recommended for prophylaxis of bone infection.

Acknowledgments Open access funding provided by University of Innsbruck and Medical University of Innsbruck. This study was supported by the Unit for Experimental Orthopedics, Department for Orthopedic Surgery, Medical University Innsbruck and by telos GmbH, Marburg, Germany. We would like to thank Andrea Windisch and Nina Schrenk for the technical support. All the substances were kindly donated by Heraeus Medical GmbH (Wehrheim, Germany).

Open Access This article is distributed under the terms of the Creative Commons Attribution 4.0 International License (http:// creativecommons.org/licenses/by/4.0/), which permits unrestricted use, distribution, and reproduction in any medium, provided you give appropriate credit to the original author(s) and the source, provide a link to the Creative Commons license, and indicate if changes were made.

\section{References}

Alt V, Bechert T, Steinrucke P, Wagener M, Seidel P, Dingeldein E, Domann E, Schnettler R (2004) In vitro testing of antimicrobial activity of bone cement. Antimicrob Agents Chemother 48(11):4084-4088

Arciola C, Gamberini S, Campoccia D, Visai L, Speziale P, Baldassarri L, Montanaro L (2005) A multiplex PCR method for the detection of all five individual genes of ica locus in Staphylococcus epidermidis. A survey on 400 clinical isolates from prosthesis-associated infections. J Biomed Mater Res Part A 75A(2):408-413

Ascherl R (2010) Infection management of megaimplants. Orthopade 39(10):980-993

Barbour SA, King W (2003) The safe and effective use of allograft tissue-an update. Am J Sports Med 31(5):791-797

Barckman J, Baas J, Sorensen M, Lange J, Bechtold JE, Soballe K (2014) Does tobramycin impregnation of allograft bone affect implant fixation?-an experimental study in 12 dogs. J Biomed Mater Res B Appl Biomater 102(1):173-180

Blom AW, Taylor AH, Pattison G, Whitehouse S, Bannister GC (2003) Infection after total hip arthroplasty. The Avon experience. J Bone Joint Surg Br 85(7):956-959

Brewster NT, Gillespie WJ, Howie CR, Madabhushi SP, Usmani AS, Fairbairn DR (1999) Mechanical considerations in impaction bone grafting. J Bone Joint Surg Br 81(1):118-124

Buchholz HW, Engelbrecht H (1970) Depot effects of various antibiotics mixed with Palacos resins. Chirurg 41(11):511-515

Butler AM, Morgan DA, Verheul R, Walsh WR (2005) Mechanical properties of gamma irradiated morselized bone during compaction. Biomaterials 26(30):6009-6013

Buttaro MA, Gimenez MI, Greco G, Barcan L, Piccaluga F (2005) High active local levels of vancomycin without nephrotoxicity released from impacted bone allografts in 20 revision hip arthroplasties. Acta Orthop 76(3):336-340

Buttaro MA, de la Rosa DM, Comba F, Piccaluga F (2012) High failure rate with the GAP II ring and impacted allograft bone in severe acetabular defects. Clin Orthop Relat Res 470(11):3148-3155

Christensen GD, Baddour LM, Hasty DL, Lowrance JH, Simpson WA (1989) Microbial and foreign body factors in the pathogenesis of medical device infections. In: Bisno AL, Waldvogel FA (eds) Infection associated with indwelling medical devices. American Society for Microbiology, Washington, DC, pp 4-27

Coraça-Huber DC, Fille M, Hausdorfer J, Pfaller K, Nogler M (2012a) Evaluation of MBEC-HTP biofilm model for studies of implant associated infections. J Orthop Res 30(7):1176-1180

Coraça-Huber DC, Fille M, Hausdorfer J, Pfaller K, Nogler M (2012b) Staphylococcus aureus biofilm formation and 
antibiotic susceptibility tests on polystyrene and metal surfaces. J Appl Microbiol 112(6):1235-1243

Coraça-Huber DC, Hausdorfer J, Fille M, Nogler M (2013a) Effect of storage temperature on gentamicin release from antibiotic-coated bone chips. Cell Tissue Bank 14(3):395-400. doi:10.1007/s10561-012-9339-8

Coraça-Huber DC, Putzer D, Fille M, Hausdorfer J, Nogler M, Kuhn KD (2013b) Gentamicin palmitate as a new antibiotic formulation for mixing with bone tissue and local release. Cell Tissue Bank 15(1):139-144. doi:10.1007/ s10561-013-9384-y

Coraça-Huber D, Hausdorfer J, Fille M, Nogler M, Kuhn KD (2014) Calcium carbonate powder containing gentamicin for mixing with bone grafts. Orthopedics 37(8):e669-e672. doi:10.3928/01477447-20140728-50

Coraça-Huber DC, Wurm A, Fille M, Hausdorfer J, Nogler M, Vogt S, Kuhn KD (2015) Antibiotic-loaded calcium carbonate/calcium sulfate granules as co-adjuvant for bone grafting. J Mater Sci Mater Med 26(1):5344

Costerton JW, Stewart PS, Greenberg EP (1999) Bacterial biofilms: a common cause of persistent infections. Science 284(5418):1318-1322

Ding H, Mao Y, Yu B, Zhu Z, Li H, Yu B, Huang J (2015) The use of morselized allografts without impaction and cemented cage support in acetabular revision surgery: a 4to 9-year follow-up. J Orthop Surg Res 10(1):1-8

Duffy GP, O'Connor MI, Brodersen MP (2007) Fatigue failure of the GAP ring. J Arthroplasty 22(5):711-714

Esteban J, Molina-Manso D, Spiliopoulou I, Cordero-Ampuero J, Fernandez-Roblas R, Foka A, Gomez-Barrena E (2010) Biofilm development by clinical isolates of Staphylococcus spp. from retrieved orthopedic prostheses. Acta Orthop 81(6):674-679

Evaniew N, Tan V, Parasu N, Jurriaans E, Finlay K, Deheshi B, Ghert M (2013) Use of a calcium sulfate-calcium phosphate synthetic bone graft composite in the surgical management of primary bone tumors. Orthopedics 36(2):e216e222

Folsch C, Mittelmeier W, Bilderbeek U, Timmesfeld N, von Garrel T, Peter Matter H (2012) Effect of storage temperature on allograft bone. Transfus Med Hemother 39(1):36-40

Frommelt L (2004) Guidelines on antimicrobial therapy in situations of periprosthetic THR infection. Orthopade 33(7):822-828

Frommelt L (2006) Principles of systemic antimicrobial therapy in foreign material associated infection in bone tissue, with special focus on periprosthetic infection. Injury 37(Suppl 2):S87-S94

Goldberg VM (2000) Selection of bone grafts for revision total hip arthroplasty. Clin Orthop Relat Res 381:68-76

Gristina AG (1987) Biomaterial-centered infection: microbial adhesion versus tissue integration. Science 237(4822):1588-1595

Haimi S, Vienonen A, Hirn M, Pelto M, Virtanen V, Suuronen R (2008) The effect of chemical cleansing procedures combined with peracetic acid-ethanol sterilization on biomechanical properties of cortical bone. Biologicals 36(2):99-104

Hinsenkamp M, Muylle L, Eastlund T, Fehily D, Noel L, Strong DM (2012) Adverse reactions and events related to musculoskeletal allografts: reviewed by the World Health Organisation Project NOTIFY. Int Orthop 36(3):633-641

Hofmann A, Konrad L, Hessmann MH, Kuchle R, Korner J, Rompe JD, Rommens PM (2005) The influence of bone allograft processing on osteoblast attachment and function. J Orthop Res 23(4):846-854

Inzana JA, Schwarz EM, Kates SL, Awad HA (2016) Biomaterials approaches to treating implant-associated osteomyelitis. Biomaterials 81:58-71

Isefuku S, Joyner CJ, Simpson AH (2003) Gentamicin may have an adverse effect on osteogenesis. J Orthop Trauma 17(3):212-216

Kuhn KD, Weber C, Kreis S, Holzgrabe U (2008) Evaluation of the stability of gentamicin in different antibiotic carriers using a validated MEKC method. J Pharm Biomed Anal 48(3):612-618

Kühn K, Vogt S, Schnabelrauch M (2003) Porous implants with antibiotic coating, their preparation and use. EP 1374923:B1

Lindsey RW, Probe R, Miclau T, Alexander JW, Perren SM (1993) The effects of antibiotic-impregnated autogeneic cancellous bone graft on bone healing. Clin Orthop Relat Res 291:303-312

Montanaro L, Speziale P, Campoccia D, Ravaioli S, Cangini I, Pietrocola G, Giannini S, Arciola CR (2011) Scenery of Staphylococcus implant infections in orthopedics. Future Microbiol 6(11):1329-1349

Oakes DA, Cabanela ME (2006) Impaction bone grafting for revision hip arthroplasty: biology and clinical applications. J Am Acad Orthop Surg 14(11):620-628

Parrish FF (1973) Allograft replacement of all or part of the end of a long bone following excision of a tumor. J Bone Joint Surg Am 55(1):1-22

Parvizi J, Pour AE, Keshavarzi NR, D’Apuzzo M, Sharkey PF, Hozack WJ (2007) Revision total hip arthroplasty in octogenarians. A case-control study. J Bone Joint Surg Am 89(12):2612-2618

Parvizi J, Saleh KJ, Ragland PS, Pour AE, Mont MA (2008) Efficacy of antibiotic-impregnated cement in total hip replacement. Acta Orthop 79(3):335-341

Parvizi J, Azzam K, Ghanem E, Austin MS, Rothman RH (2009) Periprosthetic infection due to resistant staphylococci: serious problems on the horizon. Clin Orthop Relat Res 467(7):1732-1739

Patel R (2005) Biofilms and antimicrobial resistance. Clin Orthop Relat Res 437:41-47

Phillips JE, Crane TP, Noy M, Elliott TS, Grimer RJ (2006) The incidence of deep prosthetic infections in a specialist orthopaedic hospital: a 15-year prospective survey. J Bone Joint Surg Br 88(7):943-948

Putzer D, Mayr E, Haid C, Reinthaler A, Nogler M (2011) Impaction bone grafting: a laboratory comparison of two methods. J Bone Joint Surg Br 93(8):1049-1053

Roberts R, McConoughey SJ, Calhoun JH (2013) Size and composition of synthetic calcium sulfate beads influence dissolution and elution rates in vitro. J Biomed Mater Res B Appl Biomater 102(4):667-673. doi:10.1002/jbm.b.33045

Saraf SK, Yadav A, Nagwani S, Sen M (2010) Decal bone matrix as a local antibiotic delivery vehicle in a MRSAinfected bone model: an experimental study. Indian J Orthop 44(3):246-251 
Schäfer P, Fink B, Sandow D, Margull A, Berger I, Frommelt L (2008) Prolonged bacterial culture to identify late periprosthetic joint infection: a promising strategy. Clin Infect Dis 47(11):1403-1409

Schwotzer N, Wahl P, Fracheboud D, Gautier E, Chuard C (2014) Optimal culture incubation time in orthopedic device-associated infections: a retrospective analysis of prolonged 14-day incubation. J Clin Microbiol 52(1):61-66

Sorger JI, Hornicek FJ, Zavatta M, Menzner JP, Gebhardt MC, Tomford WW, Mankin HJ (2001) Allograft fractures revisited. Clin Orthop Relat Res 382:66-74

Stevens CM, Tetsworth KD, Calhoun JH, Mader JT (2005) An articulated antibiotic spacer used for infected total knee arthroplasty: a comparative in vitro elution study of Simplex and Palacos bone cements. J Orthop Res 23(1):27-33

Tagil M, Aspenberg P (1998) Impaction of cancellous bone grafts impairs osteoconduction in titanium chambers. Clin Orthop Relat Res 352:231-238

Toms AD, Barker RL, Jones RS, Kuiper JH (2004) Impaction bone-grafting in revision joint replacement surgery. J Bone Joint Surg Am 86-A(9):2050-2060

Wichelhaus TA, Dingeldein E, Rauschmann M, Kluge S, Dieterich R, Schafer V, Brade V (2001) Elution characteristics of vancomycin, teicoplanin, gentamicin and clindamycin from calcium sulphate beads. J Antimicrob Chemother 48(1):117-119

Winkler H, Janata O, Berger C, Wein W, Georgopoulos A (2000) In vitro release of vancomycin and tobramycin from impregnated human and bovine bone grafts. J Antimicrob Chemother 46(3):423-428

Winkler H, Kaudela K, Stoiber A, Menschik F (2006) Bone grafts impregnated with antibiotics as a tool for treating infected implants in orthopedic surgery-one stage revision results. Cell Tissue Bank 7(4):319-323

Winkler H, Stoiber A, Kaudela K, Winter F, Menschik F (2008) One stage uncemented revision of infected total hip replacement using cancellous allograft bone impregnated with antibiotics. J Bone Joint Surg Br 90(12):1580-1584

Witso E, Persen L, Benum P, Bergh K (2002) Release of netilmicin and vancomycin from cancellous bone. Acta Orthop Scand 73(2):199-205

Witso E, Persen L, Benum P, Bergh K (2005) Cortical allograft as a vehicle for antibiotic delivery. Acta Orthop 76(4):481-486

Zimmerli W, Trampuz A, Ochsner PE (2004) Prosthetic-joint infections. N Engl J Med 351:1645-1654 